\title{
Koordinasi Proteksi Sebagai Upaya Pencegahan Terjadinya Sympathetic Trip Di Kawasan Tursina, PT. Pupuk Kaltim
}

\author{
Ekka Sheilla Calmara, Margo Pujiantara, Sjamsjul Anam \\ Jurusan Teknik Elektro - FTI - Institut Teknologi Sepuluh Nopember (ITS) \\ Jl. Arief Rahman Hakim, Surabaya 60111 \\ E-mail: margo@ee.its.ac.id, anam@ee.its.ac.id
}

\begin{abstract}
Abstrak - Semakin besar jumlah gangguan, berarti keandalan sistem makin rendah begitu juga sebaliknya. Salah satu gangguan yang sering terjadi adalah Sympathetic Trip Peristiwa ini pada umumnya disebut trip ikutan atau palsu. Hal ini dapat mengganggu keandalan system dan kontinuitas sistem jaringan yang sehat. Seperti pada PT. Pupuk Kaltim, saat ada gangguan terjadi di Tursina, terjadi trip simpatetik di island lain, di Kanibungan karena arus gangguan yang dirasakan terlalu besar, yakni mencapai $8.141 \mathrm{kA}$. Oleh sebab itu untuk mengurangi arus gangguan hubung singkat tersebut digunakan suatu impedansi tambahan yaitu Insulated Transformer. Trafo ini dipasang pada bagian outgoing Tursina menuju ring PT. Pupuk Kaltim Pemasangan Trafo dapat mengurangi besarnya arus hubung singkat menjadi $1.75 \mathrm{kA}$. Pemasangan Insulated Transformer sebesar 25 MVA menunjukkan arus hubung singkat semakin berkurang sehingga mengakibatkan terjadinya perubahan koordinasi proteksi rele arus lebih pada Tursina. Hasil analisa hubung singkat serta studi koordinasi proteksi akan ditampilkan dalam bentuk kurva time current characteristic (TCC)
\end{abstract}

Kata Kunci : Insulated Transformer, Koordinasi Proteksi, Rele Arus Lebih, Sympathetic Trip, Time Current Characteristic (TCC)

\section{PENDAHULUAN}

$\mathrm{P}$ T. Pupuk Kaltim merupakan salah satu perusahaan yang bergerak dalam penyediaan pupuk, Tursina merupakan salah satu area pabrik dan pelabuhan di PT. Pupuk Kaltim. Untuk mengurangi gangguan, dalam rangka mempertahankan keandalan sistem diperlukan suatu sistem koordinasi proteksi yang tepat untuk suatu sistem dari berbagai gangguan yang kemungkinan terjadi. Apabila peralatan proteksi memberikan respon yang salah terhadap gangguan akan terjadi gangguan, salah satu gangguan yang terjadi adalah gangguan yang dikenal sebagai gangguan Sympathetic Trip, dimana suatu sistem proteksi pada jaringan yang sehat ikut terganggu dan trip akibat jaringan yang terganggu, Peristiwa ini pada umumnya disebut dengan trip ikutan atau palsu. Sistem Kelistrikan di PT. Pupuk Kaltim tidak lepas dari beberapa gangguan, salah satunya adalah gangguan sympathetic trip yang terjadi di Kawasan Tursina. Hal ini menyebabkan rele di kawasan Kanibungan terjadi trip karena arus kontribusi dari Kanibungan menuju Tursina terlalu besar, sehingga dibutuhkan impedansi tambahan untuk mengurangi arus gangguannya, sehingga perlu dilakukan koordinasi ulang sistem proteksi Tursina setelah penambahan trafo tersebut. Analisa hubung singkat serta studi koordinasi dalam bentuk time current curve (TCC) disimulasikan menggunakan software ETAP.

\section{TEORI PENUNJANG}

\section{A. Gangguan Hubung Singkat}

Dalam setiap sistem kelistrikan di industri tidak dapat lepas dari kemungkinan adanya gangguan, baik gangguan yang bersumber dari dalam sistem sendiri (internal) maupun dari luar (external). Gangguan yang sering terjadi pada suatu sistem kelistrikan industri adalah gangguan hubung singkat. Gangguan ini dapat menyebabkan beberapa dampak antara lain arus hubung singkat akan sangat tinggi, tegangan akan menjadi drop, serta terputusnya aliran daya. Besarnya arus gangguan hubung singkat dapat ditentukan berdasarkan impedansi dari peralatan listrik pada sistem tersebut. Gangguan hubung singkat dapat terjadi tiga fasa, dua fasa, satu fasa ke tanah, dua fasa ke tanah, atau 3 fasa ke tanah. Gangguan hubung singkat simetri atau disebut gangguan hubung singkat seimbang yaitu terjadi pada gangguan hubung singkat tiga fasa.

\section{B. Sympathetic Trip}

Dalam sistem tenaga listrik diperlukan sistem tenaga listrik yang dapat menjamin keandalan dan kesinambungan penyaluran, jumlah gangguan pelayanan merupakan indikator untuk mengetahui keandalan suatu jaringan. Semakin besar jumlah gangguan, berarti keandalan sistem makin rendah begitu juga sebaliknya. Salah satu gangguan yang sering terjaid pada Jaringan Tegangan Menengah adalah Sympathetic Trip dimana suatu sistem proteksi merespon secara salah atau tidak diharapkan pada suatu kondisi atau keadaan sistem yang mengalami gangguan. Peristiwa ini pada umumnya disebut trip ikutan atau palsu karena sistem proteksi yang bekerja dari jaringan yang sehat[1]

\section{Setting Rele Arus Lebih Waktu Terbalik (Invers Time)}

Rele arus lebih waktu terbalik memiliki batas setting yaitu rele tidak boleh bekerja saat beban maksimum, sehingga setting arus dari rele ini harus lebih besar dari arus beban penuh dari peralatan yang akan diamankan.

Pada rele arus lebih waktu terbalik terdiri dari dua bagian setting yaitu setting pickup dan setting time dial. Pada pickup 
besarnya arus pickup ditentukan dengan pemilihan tap. Untuk mengetahui setting rele arus lebih digunakan persamaan 2 berikut :

$$
1.05 \mathrm{I}_{\mathrm{FLA}}<\mathrm{I}_{\mathrm{set}}<1.4 \mathrm{I}_{\mathrm{FLA}}
$$

Setting time dial digunakan untuk menentukan waktu operasi rele. Untuk menentukan nilai time dial dari masingmasing kurva karakteristik invers rele arus lebih dapat digunakan persamaan 3 dibawah.

$$
t d=\frac{k \times T}{\beta \times\left[\left(\frac{I}{\text { Iset }}\right)^{\alpha}-1\right]}
$$

Dimana :

$$
\begin{aligned}
& \text { td = waktu operasi (detik) } \\
& \mathrm{T}=\text { time dial } \\
& \text { I } \quad=\text { nilai arus (Ampere) } \\
& \mathrm{I}_{\mathrm{set}} \quad=\text { arus pickup (Ampere) } \\
& \mathrm{k}=\text { koefisien invers } 1 \text { (lihat pada tabel } 1) \\
& \alpha \quad=\text { koefisien invers } 2 \text { (lihat pada tabel 1) } \\
& \beta=\text { koefisien invers } 3 \text { (lihat pada tabel 1) }
\end{aligned}
$$

Tabel 1.

Koefisien invers time dial

\begin{tabular}{llcc}
\hline \hline Tipe Kurva & \multicolumn{3}{c}{ Koefisien } \\
& \multicolumn{1}{c}{$\boldsymbol{\alpha}$} & $\boldsymbol{\beta}$ \\
\hline Standard Inverse & 0.14 & 0.02 & 2.970 \\
Very Invers & 13.50 & 1.00 & 1.500 \\
Extremely Inverse & 80.0 & 2.00 & 0.808 \\
\hline \hline
\end{tabular}

\section{a) Setting Rele Arus Lebih Seketika (Instantaneous)}

rele arus lebih seketika ini akan bekerja seketika jika ada arus lebih yang mengalir melebihi batas yang diijinkan. Untuk menentukan setting pickup dari rele arus lebih seketika dengan menggunakan nilai $\mathrm{I}_{\mathrm{SC}}$ min atau nilai arus hubung singkat antar fasa $\left(I h s_{2 \varphi}\right)$ pada pembangkitan minimum. Persamaan 4 dibawah memperlihatkan setting dari rele arus lebih seketika :

$$
\text { Iset } \leq \mathrm{I}_{\mathrm{SC}} \min
$$

Dalam melakukan setting rele arus lebih seketika terdapat pertimbangan khusus pada pengaman feeder yang dipisahkan oleh sebuah transformator yang diperlihatkan pada gambar 3. Persamaan yang digunakan dalam menentukan setting pickup adalah sebagai berikut :

$$
\mathrm{I}_{\mathrm{SC} \text { max bus } 2} \leq \mathrm{Iset} \leq 0.8 \times \mathrm{I}_{\mathrm{SC} \text { min bus } 1}
$$

Dimana nilai $\mathrm{I}_{\mathrm{sc}} \max$ bus 2 merupakan nilai arus hubung singkat tiga fasa maksimum $\left(I h s_{3 \varphi}\right)$ pada titik 2, sedangkan $\mathrm{I}_{\mathrm{SC} \text { min bus } 1}$ merupakan arus hubung singkat minimum pada titik 1. Jika persamaan 5 terpenuhi maka setting time delay pada rele diatas transformator boleh kembali pada time delay 0.1 .

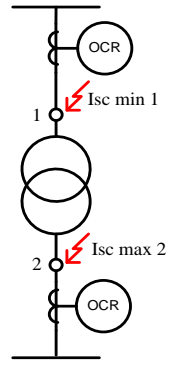

Gambar 1. Rele arus lebih pengaman transformator

\section{SISTEM KELISTRIKAN KAWASAN TURSINA PT. PUPUK KALTIM}

\section{A. Sistem Kelistrikan Kawasan Tursina, PT. Pupuk Kaltim}

PT. Pupuk Kaltim merupakan salah satu perusahaan yang bergerak dalam penyediaan pupuk, Tursina merupakan salah satu area pabrik dan pelabuhan di PT. Pupuk Kaltim yang berada di Bontang. Saat ini PT. Pupuk Kaltim disuplai oleh beberapa sumber kelistrikan untuk setiap island yaitu Kawasan Kanibungan, KDM, Kaltim-4, Kaltim-3, Kaltim-2 dan Tanjung Harapan dan sebuah grid PLN yang terletak di Kawasan Tursina. Single line diagram Kawasan Tursina, PT. Pupuk Kaltim dapat dilihat pada Gambar 2 di bawah ini.

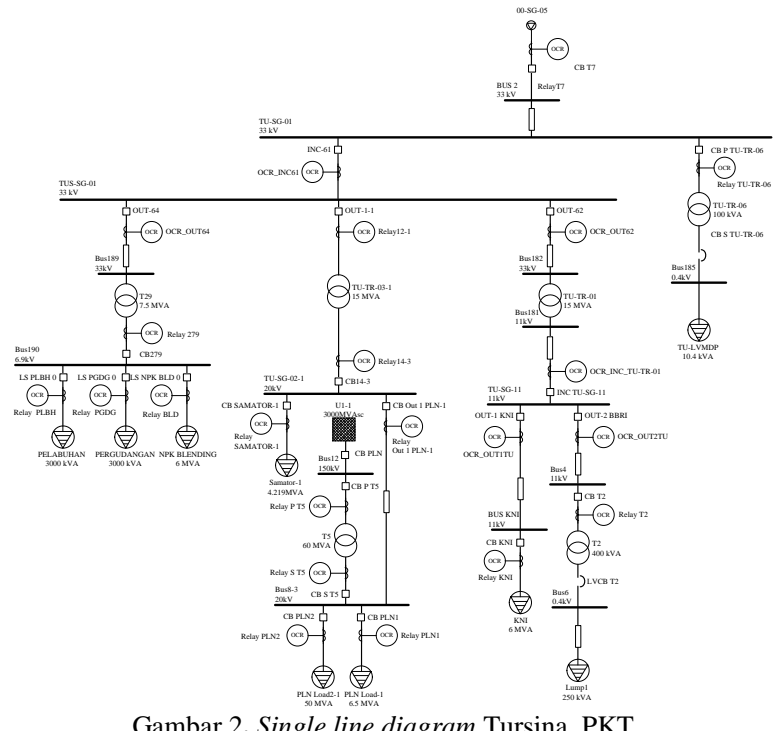

Jaringan distribusi PT. Pupuk Kaltim menggunakan system ring dan radial untuk setiap island nya. PT. Pupuk Kaltim memiliki 6 unit generator yang tersebar di seluruh PT. Pupuk Kaltim, di antaranya Kawasan Kanibungan, KDM, Kaltim-4, Kaltim-3, Kaltim-2 dan Tanjung Harapan. Berikut adalah data - data pembangkitnya pada tabel 2.

Tabel 2.

Data Pembangkit Kawasan Tursina, PT. Pupuk Kaltim.

\begin{tabular}{ccccccc}
\hline \hline NO & ID & $\begin{array}{c}\text { Teg } \\
(\mathrm{kV})\end{array}$ & $\begin{array}{c}\text { PF } \\
(\%)\end{array}$ & $\begin{array}{c}\text { Daya } \\
(\text { MVA })\end{array}$ & $\begin{array}{c}\text { FLA } \\
(\text { Amp })\end{array}$ & $\begin{array}{c}\text { Xd” } \\
(\%)\end{array}$ \\
\hline 1 & STG K-5 & 11 & 80 & 30 & 1968 & 19.1 \\
2 & GTG-KDM & 11 & 80 & 34 & 2231 & 16.9 \\
3 & GEN-P & 11 & 80 & 21.6 & 1417 & 16.1 \\
4 & 16-Z-001 & 11 & 80 & 30 & 1968 & 12 \\
5 & GTG K2 & 11 & 80 & 36.4 & 2388 & 25 \\
6 & PKT-STG-2 & 11 & 80 & 36 & 2362 & 19.1 \\
\hline
\end{tabular}

\section{SIMULASI DAN ANALISA KAWASAN TURSINA, PT. PUPUK KALTIM}

\section{A. Simulasi Sympathetic Trip}

Dilakukan analisa sequence-of operation untuk mengetahui kerja breaker dan rele pengaman. Analisa sequence dilakukan dengan melakukan hubung singkat pada seluruh bus di plant eksisting Kawasan Tursina, PT. Pupuk Kaltim. Pada saat 
gangguan terjadi di Tursina pada bus TUS-SG-01 dan Bus TU-SG-01, terjadi trip simpatetik di Kanibungan.

Tabel 3.

\begin{tabular}{ccccc}
\multicolumn{5}{c}{ Sequence trip simpatetik } \\
\hline \hline $\begin{array}{c}\text { Time } \\
(\mathrm{mS})\end{array}$ & ID & If & Condition & Lokasi \\
\hline 100 & OCR_INCK5 & 8.141 & Phase-OC1-50 & Kanibungan \\
100 & OCR_OUT71 & 2.714 & Phase-OC1-50 & Kanibungan \\
100 & OCR_SP51 & 17.018 & Phase-OC1-50 & Ring PKT \\
176 & OCR_CP51 & 14.014 & Phase-OC1-51 & Ring PKT \\
\hline
\end{tabular}

Bisa dilihat pada Tabel 3, bahwa gangguan yang bersumber pada kawasan Tursina dirasakan oleh rele-rele di kawasan Kanibungan dikarenakan arus gangguan dari kawasan Kanibungan menuju Tursina terlalu besar diantaranya adalah Rele OCR_INCK5 yang merasakan adanya arus gangguan sebesar 8,141 .

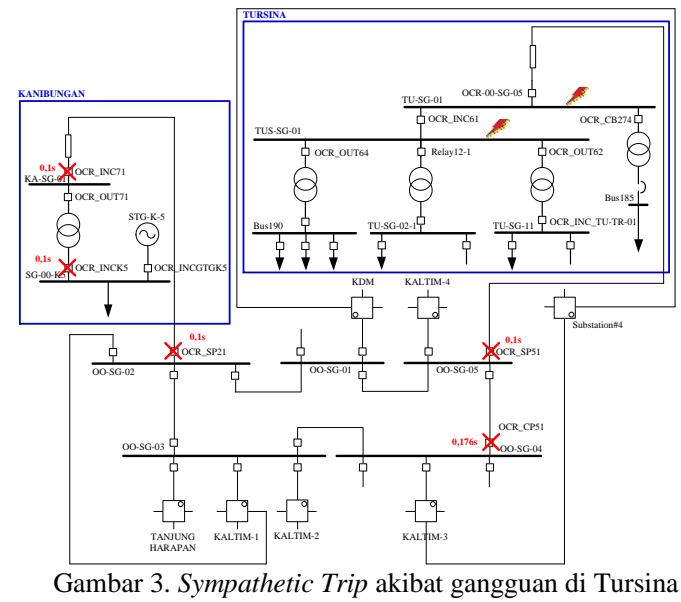

\section{B. Analisa Pemasangan Impedansi}

Di antara Kawasan Tursina dan Kanibungan hanya dihubungkan oleh kabel dengan impedansi yang nilainya relatif terlalu kecil untuk arus gangguan yang muncul dan ternyata tidak cukup untuk menahan arus hubung singkat menuju Tursina saat terjadi gangguan yang berasal dari Tursina sehingga dibutuhkan impedansi tambahan untuk mengurangi arus gangguan tersebut.

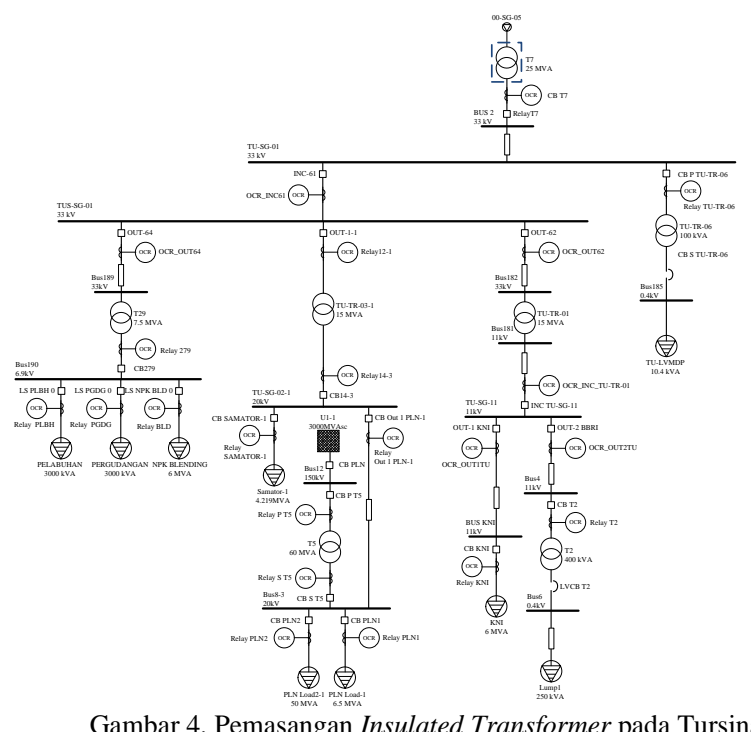

Diberikan sebuah impedansi berupa Insulated Transformer. Pemilihan trafo sebagai impedansi tambahan adalah karena Trafo juga dapat mengatasi drop tegangan pada bus dengan mengaktifkan LTC (Load Tap Changer) nya. Insulated Transformer dipasang pada bagian outgoing Tursina menuju ring PKT seperti pada Gambar 4. Seperti diperlihatkan pada Gambar 5 di bawah, bahwa setelah pemasangan Insulated Transformer, sympathetic trip sudah tidak terjadi, rele arus lebih pada Kanibungan sudah tidak merasakan adanya gangguan yang berasal dari Tursina.

Sehingga, sebuah koordinasi proteksi ulang akan dilakukan akibat pemasangan Insulated Transformer tersebut menyebabkan arus kontribusi dari Tursina berubah. Berikut ini adalah tabel 4 dan 5 yang menunjukkan perbandingan arus hubung singkat 30 cycle dan 4 cycle pada Tursina sebelum dan sesudah pemasangan Insulated Transformer.

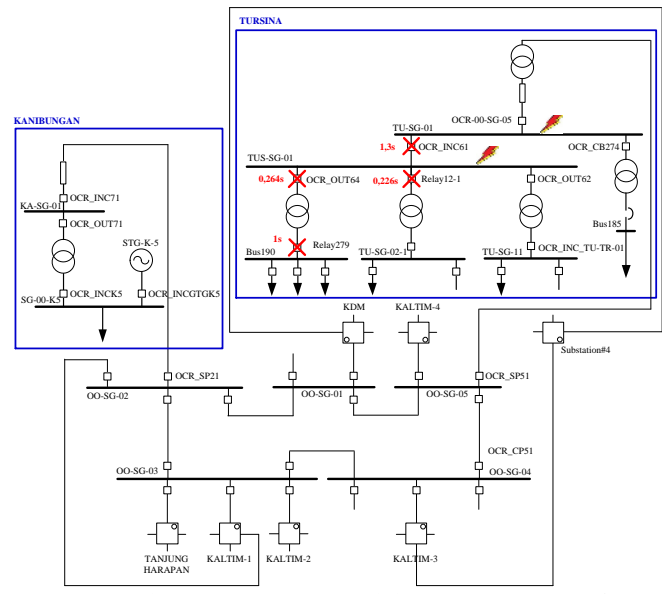

Gambar 5. Sequence setelah pemasangan Trafo

Tabel 4.

Arus Hubung Singkat Minimum 30 cycle Arus Hubung Singkat Minimum ID Bus 30 cycle 


\begin{tabular}{ccc}
\cline { 2 - 3 } & $\begin{array}{c}\text { Sebelum pemasangan } \\
\text { Insulated Transformer }\end{array}$ & $\begin{array}{c}\text { Sesudah pemasangan } \\
\text { Insulated Transformer }\end{array}$ \\
\hline 4 & 4.17 & 4.04 \\
$8-3$ & 13.14 & 13.14 \\
6 & 11.32 & 12.85 \\
12 & 10.3 & 11.55 \\
16 & 5.22 & 4.84 \\
181 & 5.47 & 5.02 \\
182 & 9.21 & 4.63 \\
185 & 1.72 & 1.98 \\
189 & 8.32 & 4.42 \\
190 & 6.5 & 6.3 \\
KNI & 5.22 & 4.84 \\
TU-SG-01 & 9.23 & 4.63 \\
TU-SG-02-1 & 9.68 & 9.79 \\
TU-SG-11 & 5.46 & 5.02 \\
TUS-SG-01 & 9.23 & 4.63 \\
\hline
\end{tabular}

Tabel 5.

Arus Hubung Singkat Maksimum 4cycle

\begin{tabular}{ccc}
\hline \hline \multirow{2}{*}{ ID Bus } & \multicolumn{2}{c}{ Arus Hubung Singkat Maksimum 4 cycle } \\
\cline { 2 - 3 } & $\begin{array}{c}\text { Sebelum pemasangan } \\
\text { Insulated Transformer }\end{array}$ & $\begin{array}{c}\text { Sesudah pemasangan } \\
\text { Insulated Transformer }\end{array}$ \\
\hline 4 & 5.67 & 5 \\
$8-3$ & 19.32 & 18.43 \\
6 & 13.24 & 13.11 \\
12 & 11.55 & 11.55 \\
16 & 6.5 & 5.24 \\
181 & 6.83 & 5.45 \\
182 & 17.21 & 5.9 \\
185 & 2.01 & 1.98 \\
189 & 14.95 & 5.41 \\
190 & 11.6 & 10.32 \\
KNI & 6.5 & 5.24 \\
TU-SG-01 & 17.62 & 6.26 \\
TU-SG-02-1 & 13.29 & 11.96 \\
TU-SG-11 & 6.82 & 5.44 \\
TUS-SG-01 & 17.62 & 6.26 \\
\hline
\end{tabular}

\section{Tipikal 2}

Koordinasi rele arus lebih tipikal 2 merupakan jalur tipikal dari Trafo TU-TR-03-1 hingga beban lump PLN-Load1 yang terdiri dari rele Relay PLN1 untuk melindungi beban lump PLN Load-1, rele OUT1 PLN-1 sebagai backup nya, rele Relay 14-3 sebagai pelindung trafo sekunder dan Bus8-3 serta rele Relay12-1 sebagai pelindung trafo primer dan backup rele Relay14-3. Single line diagram tipikal 1 ditunjukkan pada gambar 6 dibawah.

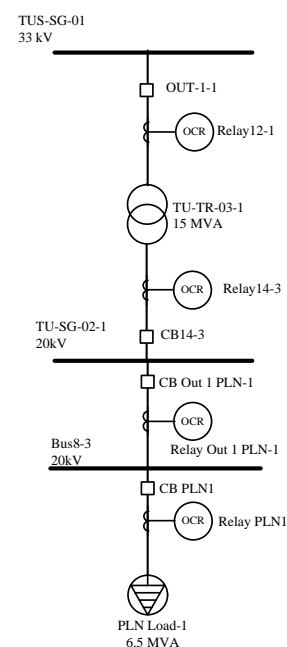

Gambar 6. Single line diagram tipikal 2

Hasil plot kurva kerja rele awal dapat dilihat pada gambar 7. Berdasarkan hasil plot tersebut terdapat beberapa perbaikan karena perubahan nilai arus hubung singkat akibat pemasangan Insulated Transformer.

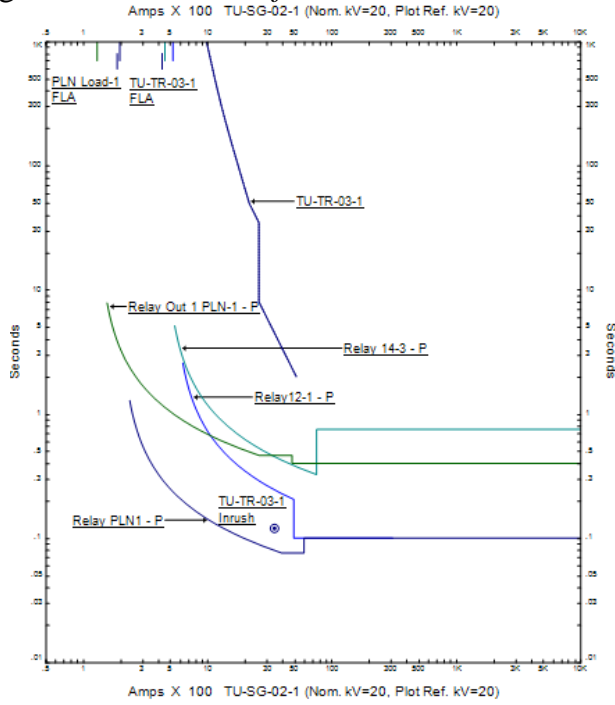

Gambar 7. Hasil Plot setelan rele existing tipikal 2

Perhitungan ulang setting rele adalah sebagai berikut :

\section{- $\quad$ Rele PLN1}

Manufaktur

Model

: Merlin Gerin

Tipe Kurva

: Sepam 1000

Rasio CT

: Standard Inverse

FLA beban lump PLN Load2-1

: 200/5

Isc min Bus8-3

$: 187.6 \mathrm{~A}$

Isc max kontribusi beban lump

$: 12290 \mathrm{~A}$

: 405A

Time Overcurrent Pickup (Low Set)

1,05 FLA beban Lump $<\mathrm{I}_{\text {set }}<1,4$ FLA beban Lump $1,05 \times 187.6<\mathrm{I}_{\text {set }}<1,4 \times 187.6$

$196.98<\mathrm{I}_{\text {set }}<262.64$

$\frac{196.98}{\text { primer CT }} \mathrm{I}_{\mathrm{n}}<$ tap $<\frac{262.64}{\text { primer CT }} \mathrm{I}_{\mathrm{n}}$ 


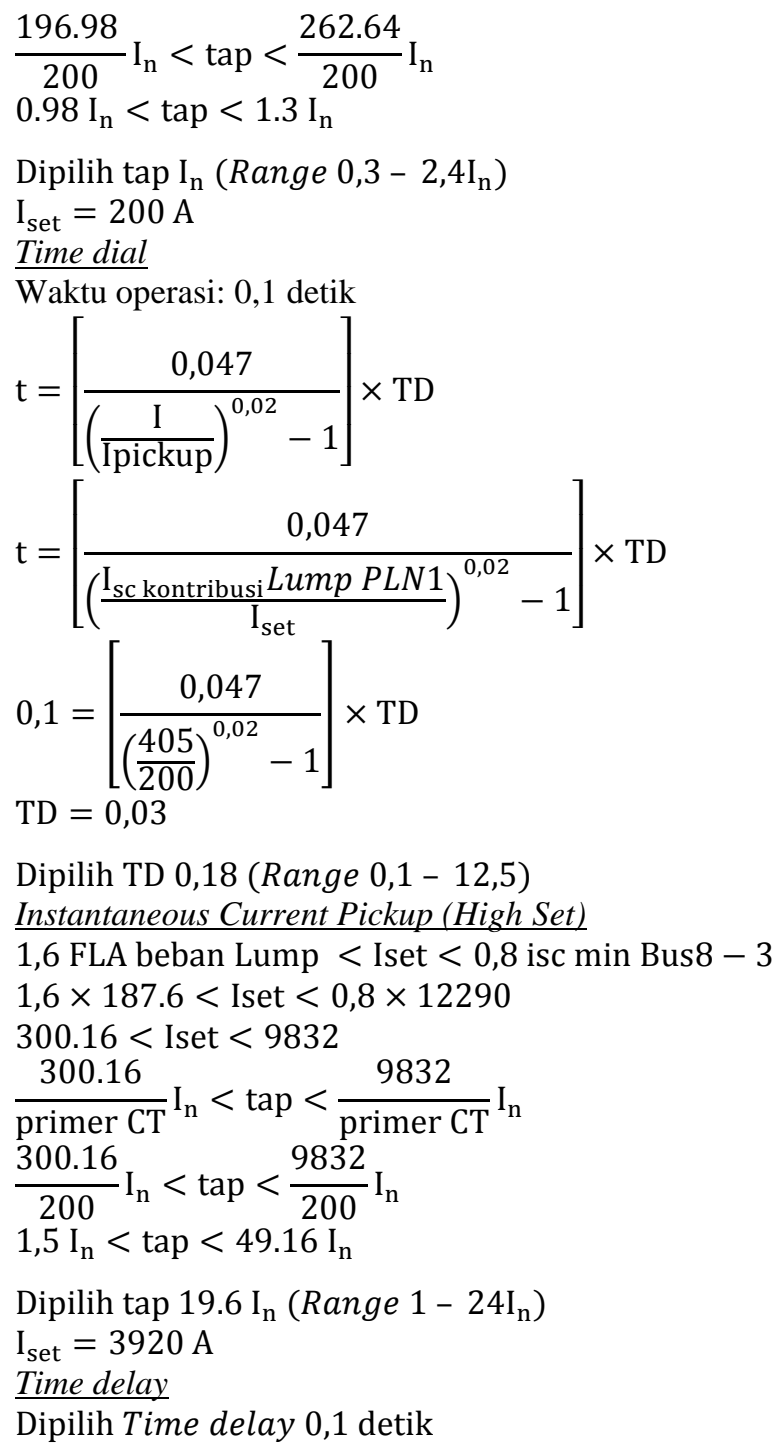

\section{- $\quad$ Rele OCR_Out 1 PLN-1}

Manufaktur

Model

Tipe Kurva

Rasio CT

FLA

Isc min bus TU-SG-02-1

Merlin Gerin

: Sepam 1000

: Standard Inverse

$: 200 / 5$

$: 175 \mathrm{~A}$

$: 12290 \mathrm{~A}$

Isc max kontribusi bus TU-SG-02-1 : 2940A

\section{Time Overcurrent Pickup (Low Set)}

1,05 FLA $<\mathrm{I}_{\text {set }}<1,4$ FLA

$1,05 \times 175<\mathrm{I}_{\text {set }}<1,4 \times 175$

$183.7<\mathrm{I}_{\text {set }}<245$

$\frac{183.7}{\text { primer CT }} \mathrm{I}_{\mathrm{n}}<$ tap $<\frac{245}{\text { primer CT }} \mathrm{I}_{\mathrm{n}}$

$\frac{183.7}{200} \mathrm{I}_{\mathrm{n}}<\operatorname{tap}<\frac{245}{200} \mathrm{I}_{\mathrm{n}}$

$0,91 \mathrm{I}_{\mathrm{n}}<\operatorname{tap}<1.2 \mathrm{I}_{\mathrm{n}}$

Dipilih tap 0,93 $\mathrm{I}_{\mathrm{n}}$ (Range 0,3 - 2,4 $\mathrm{I}_{\mathrm{n}}$ )
$\mathrm{I}_{\text {set }}=186 \mathrm{~A}$

Time dial

Waktu operasi: 0,3 detik

$\mathrm{t}=\left[\frac{0,047}{\left(\frac{\mathrm{I}}{\text { Ipickup }}\right)^{0,02}-1}\right] \times \mathrm{TD}$

$\mathrm{t}=\left[\frac{0,047}{\left(\frac{\mathrm{I}_{\text {sc max kontribusi lump }}}{\mathrm{I}_{\text {set }}}\right)^{0,02}-1}\right] \times \mathrm{TD}$

$0,3=\left[\frac{0,047}{\left(\frac{2940}{186}\right)^{0,02}-1}\right] \times \mathrm{TD}$

$\mathrm{TD}=0.35$

Dipilih TD 0.36 (Range 0,1 - 12,5)

Instantaneous Current Pickup (High Set)

1,6 FLA $<$ Iset $<0,8$ isc min kontribusi

$1,6 \times 175<$ Iset $<0,8 \times 12290$

$280<$ Iset $<9832$

$\frac{280}{\text { primer CT }} \mathrm{I}_{\mathrm{n}}<$ tap $<\frac{9832}{\text { primer CT }} \mathrm{I}_{\mathrm{n}}$

$\frac{280}{200} \mathrm{I}_{\mathrm{n}}<\operatorname{tap}<\frac{9832}{200} \mathrm{I}_{\mathrm{n}}$

$1,4 \mathrm{I}_{\mathrm{n}}<\operatorname{tap}<49.16 \mathrm{I}_{\mathrm{n}}$

Dipilih tap $8.5 \mathrm{I}_{\mathrm{n}}$ (Range $1-24 \mathrm{I}_{\mathrm{n}}$ )

$\mathrm{I}_{\mathrm{set}}=1700 \mathrm{~A}$

Time delay

Dipilih Time delay 0,3 detik

\section{- $\quad \underline{\text { Rele 14-3 }}$}

Manufaktur

Model

: Merlin Gerin

Tipe Kurva

: Sepam 1000

Rasio CT

: Standard Inverse

FLA trafo TU-TR-03-1

: 500/5

Isc min bus TU-SG-02-1

: 433

Isc max kontribusi TU-SO

Time Overcurrent Pickup (Low Set)

1,05 FLA trafo $<\mathrm{I}_{\text {set }}<1,4$ FLA Trafo

$1,05 \times 433<\mathrm{I}_{\text {set }}<1,4 \times 433$

$454,65<\mathrm{I}_{\text {set }}<606,2$

$\frac{454,65}{\text { primer CT }} \mathrm{I}_{\mathrm{n}}<\operatorname{tap}<\frac{606,2}{\text { primer CT }} \mathrm{I}_{\mathrm{n}}$

$\frac{454,65}{500} \mathrm{I}_{\mathrm{n}}<\operatorname{tap}<\frac{606,2}{500} \mathrm{I}_{\mathrm{n}}$

$0,909 \mathrm{I}_{\mathrm{n}}<\operatorname{tap}<1,212 \mathrm{I}_{\mathrm{n}}$

Dipilih tap $0,92 \mathrm{I}_{\mathrm{n}}$ (Range $0,3-2,4 \mathrm{I}_{\mathrm{n}}$ )

$\mathrm{I}_{\text {set }}=460 \mathrm{~A}$

Time dial

Waktu operasi: 0,5 detik 


$$
\begin{aligned}
& \mathrm{t}=\left[\frac{0,047}{\left(\frac{\mathrm{I}}{\text { Ipickup }}\right)^{0,02}-1}\right] \times \mathrm{TD}
\end{aligned}
$$

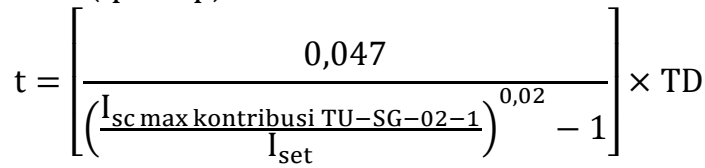

$$
\begin{aligned}
& 0,5=\left[\frac{0,047}{\left(\frac{2980}{460}\right)^{0,02}-1}\right] \times \mathrm{TD} \\
& \mathrm{TD}=0,38
\end{aligned}
$$

1,6 FLA Trafo $<$ Iset $<0,8$ isc min kontribusi TU-SG-

$$
02-1
$$

$1,6 \times 433<$ Iset $<0,8 \times 2160$

$692,8<$ Iset $<1728$

$$
\begin{aligned}
& \frac{692,8}{\text { primer CT }} \mathrm{I}_{\mathrm{n}}<\text { tap }<\frac{1728}{\text { primer CT }} \mathrm{I}_{\mathrm{n}} \\
& \frac{692,8}{500} \mathrm{I}_{\mathrm{n}}<\operatorname{tap}<\frac{1728}{500} \mathrm{I}_{\mathrm{n}} \\
& 1,39 \mathrm{I}_{\mathrm{n}}<\operatorname{tap}<3.456 \mathrm{I}_{\mathrm{n}} \\
& \text { Dipilih tap 3.4 } \mathrm{I}_{\mathrm{n}}\left(\text { Range } 1-24 \mathrm{I}_{\mathrm{n}}\right) \\
& \mathrm{I}_{\text {set }}=1700 \mathrm{~A} \\
& \text { Time delay } \\
& \text { Dipilih Time delay } 0,5 \text { detik }
\end{aligned}
$$

\section{- $\quad \underline{\text { Relay12-1 }}$}

Manufaktur

Model

: Merlin Gerin

Tipe Kurva

: Sepam 1000

Rasio CT

: Standard Inverse

FLA trafo TU-TR-03-1

$: 400 / 5$

Isc min bus TUS-SG-01

$: 262,4 \mathrm{~A}$

Isc max kontribusi TUS-SG-01 :2000A

Time Overcurrent Pickup (Low Set)

1,05 FLA trafo $<\mathrm{I}_{\text {set }}<1,4$ FLA Trafo

$1,05 \times 262,4<\mathrm{I}_{\text {set }}<1,4 \times 262,4$

$275,52<\mathrm{I}_{\text {set }}<367,36$

$\frac{275,52}{\text { primer CT }} I_{n}<$ tap $<\frac{367,36}{\text { primer CT }} I_{n}$

$\frac{275,52}{400} \mathrm{I}_{\mathrm{n}}<\operatorname{tap}<\frac{367,36}{400} \mathrm{I}_{\mathrm{n}}$

$0,689 I_{n}<\operatorname{tap}<0,918 I_{n}$

Dipilih tap 0,975 (Range 0,3 - 2,4I $\mathrm{I}_{\mathrm{n}}$ )

$\mathrm{I}_{\text {set }}=300 \mathrm{~A}$

Time dial

Waktu operasi: 0,1 detik

$\mathrm{t}=\left[\frac{0,047}{\left(\frac{\mathrm{I}}{\text { Ipickup }}\right)^{0,02}-1}\right] \times \mathrm{TD}$

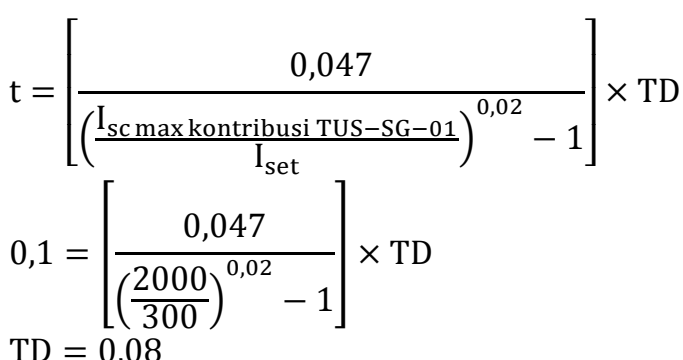

Dipilih TD 0,45 (Range 0,1 - 12,5)

Instantaneous Current Pickup (High Set)

1,6 FLA Trafo < Iset $<0,8$ isc min kontribusi TUS-SG01

$1,6 \times 262,4<$ Iset $<0,8 \times 4130$

$419,84<$ Iset $<3304$

$\frac{419,84}{\text { primer CT }} \mathrm{I}_{\mathrm{n}}<$ tap $<\frac{3304}{\text { primer CT }} \mathrm{I}_{\mathrm{n}}$

$\frac{419,84}{400} \mathrm{I}_{\mathrm{n}}<\operatorname{tap}<\frac{3304}{400} \mathrm{I}_{\mathrm{n}}$

$1,05 \mathrm{I}_{\mathrm{n}}<$ tap $<8.3 \mathrm{I}_{\mathrm{n}}$

Dipilih tap $8.2 \mathrm{I}_{\mathrm{n}}$ (Range $1-24 \mathrm{I}_{\mathrm{n}}$ )

$\mathrm{I}_{\text {set }}=3280 \mathrm{~A}$

Time delay

Dipilih Time delay 0,1 detik

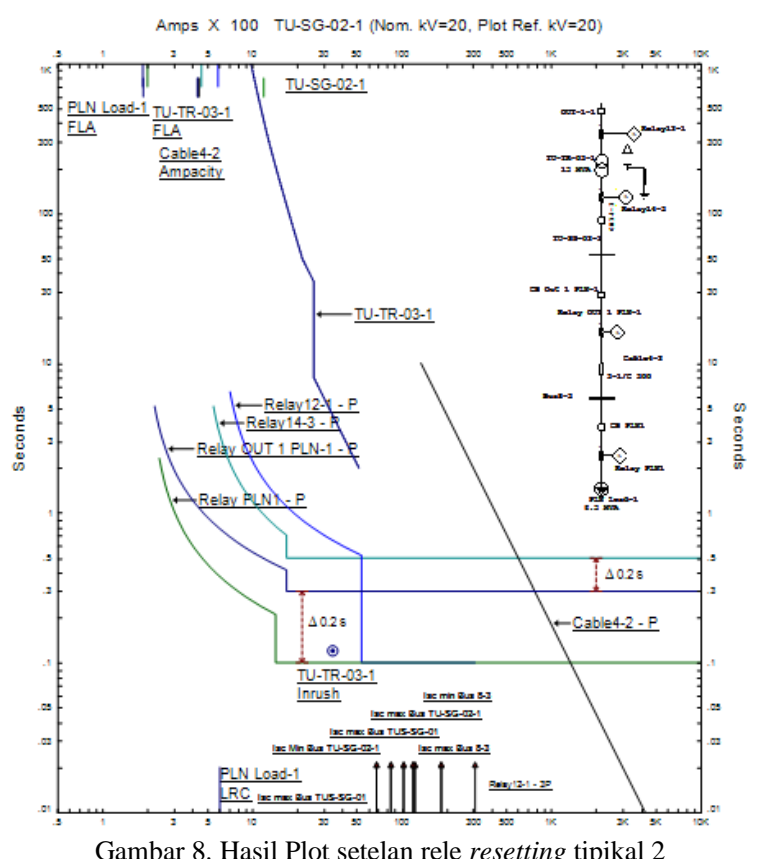

Seperti ditunjukkan pada Gambar 8. Pada plot kurva TCC tipikal 2 terlihat bahwa terjadi perubahan nilai pickup highset dari rele Relay PLN1, rele OUT1 PLN-1 dan rele Relay14-3, nilai sebelumnya terlalu besar sehingga harus diturunkan. Nilai pickup lowset dari rele OUT 1 PLN-1 dinaikkan, karena nilai existing kurang dari 1.05 FLA. Hasil setting rele overcurrent dapat dilihat pada tabel 6 di bawah. 
Tabel 6.

Hasil Setting Rele Overcurrent

\begin{tabular}{ccrcr}
\hline \hline \multirow{2}{*}{ Relay ID } & \multicolumn{4}{c}{ Setting } \\
\cline { 2 - 5 } Relay PLN1 & Eickisting Lowset & 197 & Pickup Losetting & \\
& Time dial & 0.1 & Time dial & 00 \\
& Pickup & 6000 & Pickup Highset & 0.18 \\
& Highset & & & 1440 \\
& Time delay & 0.1 & Time delay & 0.1 \\
Relay OUT & Pickup Lowset & 130 & Pickup Lowset & 186 \\
1 PLN-1 & Time dial & 0.61 & Time dial & 0.36 \\
& Pickup & 4800 & Pickup Highset & 1700 \\
& Highset & & & \\
& Time delay & 0.4 & Time delay & 0.3 \\
Relay 14-3 & Pickup Lowset & 455 & Pickup Lowset & 460 \\
& Time dial & 0.4 & Time dial & 0.4 \\
& Pickup & 7550 & Pickup Highset & 1700 \\
& Highset & & \\
& Time delay & 0.75 & Time delay & 0.5 \\
Relay 12-1 & Pickup Lowset & 320 & Pickup Lowset & 300 \\
& Time dial & 0.2 & Time dial & 0.45 \\
& Pickup & 3000 & Pickup Highset & 3280 \\
& Highset & & & \\
& Time delay & 0.1 & Time delay & 0.1 \\
\hline \hline
\end{tabular}

\section{KESIMPULAN}

Saat ada gangguan pada saat gangguan terjadi di Tursina pada bus TUS-SG-01 dan TU-SG-01, terjadi trip simpatetik di island lain, terutama pada island tanpa impedansi di bagian outgoing island seperti Kanibungan, pada rele OCR_INCK5 dan rele backup nya karena arus gangguan yang dirasakan terlalu besar, yakni mencapai $8.141 \mathrm{kA}$. Pemasangan trafo sebesar 25 MVA dengan impedansi $10 \%$ terbukti dapat mengurangi besarnya arus hubung singkat yang mengalir ke island Kanibungan menjadi sebesar $1.75 \mathrm{kA}$ sehingga sistem proteksi di Kanibungan tidak terganggu, Dengan pemasangan Insulated Transformer menunjukkan arus hubung singkat dari Tursina berkurang sehingga perlu dilakukan koordinasi ulang proteksi rele arus lebih.

\section{DAFTAR PUSTAKA}

[1] Sihombing, Mitro. "Evaluasi Koordinasi Rele Proteksi Pada Penyulang Distribusi $20 \mathrm{kV}$ Terhadap Kemungkinan Gangguan Sympathtetic Tripping Sewaktu Gangguan Satu Fasa Ke Tanah”, Jurusan Teknik Elektro Universitas Sumatera Utara, Medan, 2012.

[2] IEEE Std 551TM - 2006, "IEEE Recommended Practice for Calculating Short-Circuit Currents in Industrial and Commercial Power Systems", The Institute of Electrical and Electronics Engineers, Inc., New York, Ch. 2, 2006.

[3] Penangsang, Ontoseno."Diktat Kuliah Analisis Sistem Tenaga Listrik 2", Jurusan Teknik Elektro ITS, Surabaya

[4] Wahyudi, "Diktat Kuliah Pengaman Sistem Tenaga Listrik", Jurusan Teknik Elektro ITS, Surabaya.

[5] IEEE Std 242TM - 2001, "IEEE Recommended Practice for Protection and Coordination of Industrial and Commercial Power Systems", The Institute of Electrical and Electronics Engineers, Inc., New York, Ch. 4, Ch. 15, 2001.

[6] Tleis Nasser, "Power System Modelling and Fault Analysis", Nwenes, UK, Ch. 1, 2004

[7] Lazar, Irwin. "Electrical System Analysis and Design for Industrial Plant", McGraw-Hill Inc., USA,Ch.1, 1980

[8] Mladenovic, Slobodan. "Sympathetic Trip Prevention by Applying Simple Current Relays", 2010. 